\title{
Quality of Hospital In-use: Usability Evaluation Method as an Assessment
}

\author{
Siti Norsazlina Haron \\ Built-Environment, Universiti Teknologi MARA \\ (UiTM Malaysia), Shah Alam, Malaysia \\ E-mail: aqilmuazumar@yahoo.com.my \\ Md Yusof Hamid \\ Faculty Architecture, Planning \& Survey, Universiti Teknologi MARA (UiTM) \\ Perak. Malaysia \\ E-mail: yusof344@perak.uitm.edu.my
}

Received: December 3, 2010

Accepted: December 28, 2010

doi:10.5539/jsd.v4n2p33

\begin{abstract}
In Malaysia health-care design, developing spatial design is considered as one of the most important tasks in the preliminary design stage. In consequence, the outcome of the design gives an impact to quality of service design. The selection of quality assessment is important in support of the mission and standards of Malaysia health-care services. It is associated with a delivered a user-friendly, efficient and effective service to the patient. Hence the usability concept is attached to user's perspective evaluation very appropriate as a measurement. The purpose of this paper is to review and understanding the" usability concept" and "Usability method" as an assessment the quality of architecture in- use", and suggest a possible usability conceptual framework in achieving quality service design, which is an impact from that quality of architecture in-use. This paper will be focusing on three usability key factors; efficiency, effectiveness and users' satisfaction. This overview will help researchers in their future study to investigate the relationships between the spatial design and "usability concepts". This is done by taking into considerations the user experience of the outpatient area as part of Malaysian Primary Healthcare (MPHC) service in public hospital.
\end{abstract}

Keywords: Assessment, Outpatient spatial design, Quality service design, Usability concept

\section{Introduction: Usability Concept}

The development of primary health care is a continued support of the secondary and tertiary care. It has been an inspiration for all health systems in the world, and the momentum should be maintained to achieve the goal of health for all. MPHC is conceived in the spirit of "People First, Performance Now" towards an excellent service to people (Merican, 2010) Malaysia's health plans of policies and activities are always based on vision of Health Services, i.e.. Malaysia is to be a nation of healthy individuals, families and communities. Thus this could be achieved through a health system that is equitable, affordable, efficient, technologically appropriate, environmentally adaptable and consumer-friendly. The utmost emphasis would be on quality, innovation, health promotion and respect for human dignity, which eventually promotes individual's responsibility and community participation towards an enhanced quality of life $(\mathrm{MOH}, 2008)$

PHC in Malaysia has grown actively since Alma Ata Declaration was made in 1978; this landmark declaration formally adopted Primary Health Care as the way to provide comprehensive, universal, equitable and affordable health care for all. It is witnessed by the scenario where the hospital's expansion increases every year. Currently, throughout Malaysia there are 135 public hospitals, and our primary health care facilities had grown to 2813 health clinics. The achievement of PHC can be measured by the effectiveness and efficiency of the service delivery $(\mathrm{MOH}, 2008)$

Why users' satisfaction from a usability study is important to MPHC? MPHC is the first health treatment service for society, and it has become a focused agenda and service mission of Malaysia. Ministry of Health. Obviously, delivery service with effectiveness and efficiency will produce a service quality. Distinctly, the recent development of PHC is not just simple physicians' offices, which provide primary care, but its design has 
become independent "hospitals without beds." However, many arousing challenges to the success of PHC. One related issue is to respond to the changing users' perceptions and expectations through their experience. All in all, outpatient area is the main focus where users receive services from the hospital where daily patients present in various categories and backgrounds.

\subsection{Usability concept in built environment}

Users of the building behave in ways that the designer did not intend and wish to might be inconsistent with building performance goals. In such cases, the building may become to improved users health and performance. Designer often wished for smarter, more orderly and better-behaved users, but real building needs to accommodate real user behavior.

The study of usability emerged from a diverse field and based on some view it was first developed in the 1950s in Human Computer Interaction (Fenker, 2008; Gulliksen, 2006).Usability is widely known in relation to applications within product design, information technology and web-design. Hence it is related to user friendliness and user interface of the system. International Council for Research and Innovation in Building and Construction (CIB) Task Group 51 "Usability of buildings 2005" ,Workshop W111 - "usability of workplaces 2-2008"and "usability of workplace 3- 2010" has been established to apply concepts of usability and to provide a better understanding of the user experience of buildings and workplaces. The term usability describes user experience to service or product, whether or not a product is fit for a specific purpose. It is adopted from the international standard on usability and a part of usability parameters '[...] effectiveness, efficiency and satisfaction with a specified set of users can achieve a specified set of tasks in a particular environment' (ISO, 1998) and Usability should be addressed to 'specified users to achieve specified goals' (Alexander, 2008).

\subsection{Usability keys parameters}

A lot of usability principles and concept had been discussed and the definitions of it depends on the field of study, but mostly are determined by 3 key factors; Efficiency, Effectiveness and Satisfaction.

The efficiency of the service provided is to test how much effort and how fast does it take for a user to complete the task. The efficiency is based on a ratio of a system's service work output and its work input. These are all due to the accessibility and reach ability factors.

The effectiveness of the service provided is measured by how a user completes the tasks. Often we interpret effectiveness as the ability to reach the target we have set up; to get the desired effects of something. According to Shaw and Ivens 2002, the customer experience is a blend of company's physical performance, and the emotional evoke, intuitively measured against customer expectations across all the moments of contact (Nenonen and Rasila, 2008).

User satisfaction in common language has to do with fulfillment of a desire or a need through their feelings and attitude towards the service or product (Bahari, 2010). The phenomenon of user experiences to involve user emotion, which reflects the users satisfaction and service outcomes are of more quality (Poldma,2009; Chamorro-Koc,2007).

\section{Usability in healthcare spatial design}

Most of the studies showed that the usability is closely related to the quality and direction of service design. Hospital is classified as service-oriented and characterized by major complexity buildings. Planning and design of hospital buildings reflect a view of society, humanity and patients at all levels. It an operation is affected by rapid changes and trends and regarded as a catalyst for change in the service provision. Traditionally service organizations have set themselves strategic objectives; however, they have frequently lacked the appropriate techniques to achieve them efficiently and effectively and yet satisfied end-users (Lennerts, 2005)Recent study shows usability evaluation of hospital buildings give positive impact to hospital service.

Health care is about meeting the physical, psychological and social needs of a person who seeks care (Harun, 2008; Hsieh; Hignett, 2009).When people went to the hospital in seeking treatments, sometimes a moment, they enter the hospital entrance, the environment of the space makes them feel uncomfortable and stress full. Spatial design is about the human experience -reaction and interaction to the space. A good spatial design according to Passini and Arthur, 1992 can reduce patients stress and frustration feeling. hence functional efficiency, visitor accessibility, patient empowerment, safety, improving cognitive skills in spatial understanding and physical efforts (Huelat, 2007), It's to do the overall efficiency and effectiveness of the hospital design (Mollerup,2009).and satisfaction (Haron, 2010).Hence most of the research also has shown that design based on users experience and taking their opinion can produce a better and positive design outcome and meet organization and users goals (Behkami, 2009). 
In conventional professional view and current practice of assessment building or architecture in-use, patients may lack the knowledge to make valid judgments on the quality of outcomes (Granath, 2008).Otherwise, many of the instruments that have been developed are designed from the point of view of the health professionals or health service and often may not give enough emphasis to the needs of the patients. The quality of hospital buildings depends on the building's ability to absorb organizational, operational and technical changes (Jensø., 2005).Meeting patient expectations are the most important factor in determining their satisfaction. Hence usability is a concept derives from the user's expectation and perspective, which contribute to quality of service design as well as achieve the organization goals. Figure 1 explain the how usability affect the quality of service design. Otherwise patients have been recognized as the drivers of quality to quality improvement.

\section{Usability dimension and criteria}

Most of the usability values have been explored from design quality assessment (Voordt, 2009), and it may be assessed with several attributes or dimensions. Usability dimensions should be defined case by case and depend on the type of building purpose and goals of users or organization (22).Here are some goals and outcomes from the review body of usability study:

Journey experience:

Efficiency, Accessibility, Flexibility, Learn ability, Memorability, Prevention of errors, Navigation, Functionality, Atmosphere, Visual design, Interaction and feedback, Satisfaction, Services cape, Feeling secure, Space, Networks (Rasila,2010).

Quality architecture in use:

Reach ability \& parking facilities, Accessibility, Efficiency, Flexibility, Safety, Spatial orientation; Privacy, territoriality \& social contact, Health \& physical well-being, Sustainability (Voordt,2009).

Quality design of the patient area; (DfU and DfE)

Design for Usability (DfU) and Design for Emotion (DfE) do have a close Relation- user participation -improve process efficiency and valuable to organizations (Garde, 2008).

Quality of health-care design:

Usability derived from, generality, flexibility, elasticity, functionality-usefulness, accessibility and esthetics aspect (Jenso , 2005).

Quality learning environment:

Usability criteria are Enjoyable, Memorable and Valuable. These ratings indicate a quality assessment should affect the users and community and the realization of benefits not only focus on the performance of the physical environment such as that practiced by POE (Alexander , 2010).

Quality of use - usability attributes:

Clear, friendly, understandable, consistent, logical, efficient \& smooth, productive, ideal, predictable, organized, natural, easy to use \& learn, effective, familiar, manageable, stress Free, accessibility, integrated, Informative, Problem solving, expected, simple, complete, helpful, dependable, useful, controllable and customizable (McGee ,2004).

Components of Usability Rating Tool - tenants experience:

Usability depends on environment profile, user characteristics, knowledge, personality, age and surrounding culture. Usability attributes; image, accessibility, business Mix, functionality, atmosphere, navigation, and interaction (Alho , 2008).Usability attributes of workplace and healthcare setting; Effectiveness - can users complete tasks, achieve goals with the product, do what they want to do, and it has to do with the effect of something.

Efficiency - how much effort do users require doing the task - in some way, has to do with the ratio of a system's work output to its work input.

Satisfaction is the fulfillment of a desire (Granath ,2008).

Quality and usability of healthcare clinic service:

Improvement and addition of five original SERVQUAL (service quality) to SERVUSE (service usability) dimension -and identify five usability factors; learnability, efficiency, memorability, errors (low errors and easy to use) and satisfaction (Strawderman , 2006). 
Quality for future library design:

Way finding- Signage and initial orientation devices, accessibility, familiarity, landmark, user friendly, easy to use, Guiding, Collection organization and usability effect by demographic and experience, which will impact their initial skills (Barlow, 2007).

Indicator of redesigning the public library to inspire the use:

Users needs functional and modern, aesthetically pleasing, friendly design and that create enjoyable and memorable experiences (Swanepoel ,2010).

\section{Usability assessment method}

There are numbers of criteria in Healthcare design assessment in United Kingdom used as Achieving Excellence Design Evaluation Toolkit (AEDET), A Staff and Patient Environment Calibration Tool (ASPECT) which could e used to support AEDET Evolution to provide a more comprehensive evaluation of the design of healthcare environment. Each measurement is based on Post Occupancy Evaluation (POE). It is closely tied to the performance techniques and, traditionally a technique used in the building process is described as mandatory (Voordt,2009).

Currently practice in Malaysia health-care assessment focus on aiming to get an ISO certificate. It focused on Lab accreditation Evaluation-Particular requirements for quality and competence and quality management system (QMS).Beside ISO certificate, hospital accreditation done by Malaysian Society for Quality in Health $(\mathrm{MSQH})$ in auditing healthcare facilities and services, patient safety and continuous quality improvement. In his audit assessment, the requirement for customer satisfaction is excluded because the focus is on ensuring that regulatory requirements are fulfilled and the implementation of this requirement was considered too subjective. Compared to usability, it is emphasized on the user experience and perspective (Voordt,2009).

In this study, it meets five functions of evaluation. Firstly, to explore and reviewing the current approach in health-care design and service evaluation. Secondly, to conduct the usability evaluation of an outpatient spatial designed -feedback from the main outpatient end-users, facilities managers, medical planners and hospital management experience. Thirdly, to obtain patient responses as to usable spatial design by focusing the main issue related to effectiveness, efficiency and user satisfaction. Fourthly, to obtain data on efficiency and effectiveness of the design by proposing the usable solution for service design. Five, an understanding of users' needs and usability is developed as a design framework useful to design guide and process. In addition to improve usability within the given context hence acting as learning feature for future projects. Therefore, to achieve these objective, several methods are used in usability research are discussed in table 2 used in this study.

Usability concept outcome is for safe, comfortable and healthy indoor environments with full participation of all stakeholders in environment and health, comprising of:

New alliances and matching between demand and supply.

Innovative assessment and accessible to all people.

Become new indicators of design, operation and maintenance processes of building and network services.

\section{Usability data collection}

Usability method is the development of harmonized assessment methods from the human point of view focusing on the objective relations between stimulus and perceptual behavior. It is a system that anticipates perception and understanding of the impact of the indoor built environment by understanding the demands, desires and needs of all occupants, and understanding the information chain required and improving the information transfer. Improve and update knowledge of relevant needs for various groups of people, including users with special needs, by considering: their specific requirements, and their interaction with the different environments. Figure 2 explain the flow of assessment and indicator of dimension will be testing.

\section{Discussion}

The aim of this paper is to develop the theory of usability concept, defined usability dimensions and usability assessment framework in hospital design. It involved various literature reviews from usability methodologies and measurement indicators on how well the users can cope with the service, design, facilities and activities offered by the hospital. It is intended to assist us in conducting the pilot survey on the reaction of the hospital management, facility managers and the hospital medical planner and end-users of the usability framework and indicators. Hence, the response and information are important for main study measurement. 


\section{References}

Alexander. K. (2008). Usability Philosophy and Concepts. Usability of Workplaces 2, CIB and EuroFM. CIB reports 316.Rotterdam.

Alexander. K. (2010). Usability of learning environments. Usability of Workplaces 3, CIB reports 330.Rotterdam.

Alho. J. \& Nenonen. S. (2008). Usability of Shopping Centres. components of a usability rating tool.Usability of Workplaces 2, CIB and EuroFM. CIB reports 316.Rotterdam.

Bahari .M. B.\& Y. W. Ling. (2010). Factors Contributing to Customer Satisfaction with Community Pharmacies in Malaysia. Journal of Public Health, 18, 35-41.

Barlow.Alison \& Morris. (2007). Usability of public libraries: perspectives and experiences of new users. Proceeding World Library and Information Congress, $73^{\text {rd }}$.IFLA General Congress and Council, Libraries for the future. Durban, South Africa, $19-23$.

Behkami. N. A. \& David A. D. (2009). User centered design in complex healthcare workflows: the case of care coordination and care management redesign". AMIA 2009 Symposium Proceeding, 39-43.

Chamorro-Koc. (2007). Experience Contact- of -use and the design of the product usability. Faculty Of Built Environment and Engineering Queensland University of Technology. Dissertation Doctor Philosophy.

Fenker. M. (2008). Towards A Theoretical Framework For Usability Of Buildings. Usability of Workplaces 2.CIB and EuroFM. CIB reports 316.Rotterdam.

Garde. J. A. (2008). The Design of a new NICU Patient Area:Combining Design for Usability and Design for Emotion. Design Research Society Conference. Sheffield, UK.

Granath. A. J. \& Gilleard. J. (2008). Usability in the Workplace:Case study of Pamela Youde Eastern Hospital Hong Kong. Usability of Workplaces 2, CIB and EuroFM. CIB reports 316.Rotterdam.

Gulliksen. J. (2006). Usability Professionals-Current Practices And Future Development. Journal Interacting With Computers, 18, 568-600.

Harun. M. W. \& Ibrahim F. (2008). Human-Environment Relationship Study Of Waiting Areas In Hospitals.1st. International Conference On Built. Environment In Developing Counties (ICBED) Pulau Pinang.

Haron. S.N. Hamid. M. Y. \& Talib. A. (2010). Towards Health-Care service quality: An adaptation usability concept in healthcare design. Proceedings of Arte-Polis 3 International Conference on Creative Collaboration and the Making of Place.Bandung.

Haron. S.N. Hamid. M. Y. \& Talib. A. (2010). Towards healthcare service quality: an understanding of the usability concept in healthcare design. Proceedings of ASEAN Conference on Environmental-Behaviour Studies,Sarawak.

Hignett. S. \& Lu. J. (2009). An Investigation Of The Use Of Health Building Notes By UK Healthcare Building Designers. Journal Applied Ergonomics, 40, 608-616.

Hsieh. Y. S. (2009). Taking Patients' Voices Into Account Within Quality Systems: A Comparative Study . International Journal Of Health Care Quality Assurance ,22(3),289-299.

Huelat. B. J. (2007). Wayfinding: Design For Understanding. A Position Paper for the Environmental Standards Council of The Center for Health Design. California.

Ismail Merican. (2010). 1malaysia Clinics: Urban Poor Need Shot In the Arm .News Strait Times.http://fh.moh.gov.my/modules/news.

Jenso. M. \& Haugen. T. (2005). Usability Of Hospital Buildings :Is patient focus leading to usability in hospital buildings?. Usability Of Workplaces:Case study: Nord-Trøndelag University College Nylana,_R0stad. CIB Task Group 51.

Lennerts. K. Abel. J. Pfründer . U \&V.Sharma. (2005). Step-by-step process analysis for hospital facility management: An insight into the OPIK research project". Facilities, 23 (3/4),164 - 175.

McGee. M. Rich. A. \& Dumas J. (2004). Understanding the usability construct:user-perceived usbilitypr.Proceedings of the human factors and ergonomics society 48th annual meeting, New Orleans. Louisiana,907-911.

MOH Strategic Plan 2006 - 2010. ( 2008). Towards Achieving Better Health Through Consolidation Of Services. Ministry Of Health. Malaysia.

Mollerup. P. (2009). Wayshowing in Hospital.Australasian Medical Journal.1(10),112-114.

Nenonen. S. \& Rasila. H. (2008). Customer Journey - a method to investigate user experience. International Council for Research and Innovation in Building and Construction (CIB) reports 316. 
Poldma. T. (2009). Experiential Knowledge and rigour in research. International Conference of the DRS Special Interest Group on Experiential Knowledge. London metropolitan University.

Rasila. H. Peggie. \&Kerosuo. H. (2010). Roth Dimensions of usability assessment. Journal Of Facilities Management,8(2),143-153 .

Strawderman. L. \& Koubek. R. (2006). Quality and usability in a student health clinic. International Journal of Health Care Quality Assurance, 19 (3),225 - 236.

Swanepoel. A. \& Swanepoel. C. (2010). Redesigning the interior of an existing public library to inspire use.World library and information congress: 76th ifla general conference and assembly Gothenburg, Sweden,10-15, 2010.

Voordt. T. J. M. v. d. (2009). Quality of design and usability: a vetruvian twin. Ambiente Construído, Porto Alegre, 9,(2), 17-29.

Table 1. Usability method of assessment from body of literature

\begin{tabular}{|c|c|}
\hline Research Method and Techniques & \multirow{2}{*}{$\begin{array}{l}\text { Expectation } \\
\text { Result }\end{array}$} \\
\hline On-site observation & \\
\hline $\begin{array}{l}\text { Observing physical traces- Behavior vs. design: } \\
\text { Systematically looking at physical surrounding and reflection of previous } \\
\text { activity. } \\
\text { Focus on functional issues, } \\
\text { Adaptations for use/ Public massage/ Display of self/ Product of use / User } \\
\text { patterns }\end{array}$ & $\begin{array}{l}\text { Functional design } \\
\text { criteria .Behavior and } \\
\text { appearance } \\
\text { map design-spatial } \\
\text { information \& Efficient } \\
\text { Operation }\end{array}$ \\
\hline $\begin{array}{l}\text { Observation -Environmental behavior activities: } \\
\text { People activities \& spatial-relationship. Systematically watching people use } \\
\text { their environment - context/setting/ pattern /culture/ expected uses, new uses, } \\
\text { misuses\& opportunities. }\end{array}$ & $\begin{array}{l}\text { Support humans without } \\
\text { disturbing their activities. } \\
\text { Recognized needs } \\
\text { Full Participants. }\end{array}$ \\
\hline $\begin{array}{l}\text { Walk-through observation and } \\
\text { Cognitive walk through:: } \\
\text { User journey experience -User experience feedback surrounding design. } \\
\text { Analyses of the space and movements "tour" of the building }\end{array}$ & $\begin{array}{l}\text { Assessing different qualities } \\
\text { functions and audit of } \\
\text {-environment }\end{array}$ \\
\hline Survey & \multirow{2}{*}{$\begin{array}{l}\text { Users perspective \& } \\
\text { feedback } \\
\text { Knowing related issue \& } \\
\text { exploration related evidence } \\
\text { support survey }\end{array}$} \\
\hline $\begin{array}{l}\text { Interviews : } \\
\text { Getting the story behind a participant's experiences. Obtain in-depth } \\
\text { information around the topic. Interviews useful as follows-up to certain } \\
\text { questionnaire and support behaviors reaction }\end{array}$ & \\
\hline $\begin{array}{l}\text { Questionnaire: } \\
\text { Identify an issue to investigating using scoring. Using Structured question }\end{array}$ & $\begin{array}{l}\text { Stakeholders } \\
\text { Needs and demand }\end{array}$ \\
\hline Others methods & \multirow[b]{2}{*}{$\begin{array}{l}\text { Personal needs } \\
\text { Attach to product design. }\end{array}$} \\
\hline $\begin{array}{l}\text { Story telling and personas: } \\
\text { Expression of what user's perspective and users experience }\end{array}$ & \\
\hline $\begin{array}{l}\text { workshops : } \\
\text { Participatory Getting an idea and sharing knowledge about the conflict they } \\
\text { experienced, engaging with the group to form strategies. }\end{array}$ & $\begin{array}{l}\text { Aims and objectives as well } \\
\text { as discussing future work }\end{array}$ \\
\hline $\begin{array}{l}\text { Focus group: } \\
\text { Perspective from the specific group and organized discussion with a selected } \\
\text { group of individual discuss and comment on, from personal experience } \& \\
\text { expectation }\end{array}$ & $\begin{array}{l}\text { It limited to the ideas and } \\
\text { issues at the time of the } \\
\text { session. }\end{array}$ \\
\hline $\begin{array}{l}\text { Document analysis: } \\
\text { To know current design practice and understand a present situation. } \\
\text { Purpose to support finding }\end{array}$ & $\begin{array}{l}\text { Gap of practice } \\
\text { Lacking of data or sources. } \\
\text { Lacking of implementation }\end{array}$ \\
\hline $\begin{array}{l}\text { Mapping: } \\
\text { Using structured group interviews } \\
\text { Systematic approach for organizing information more effectively. Improve } \\
\text { operating efficiency \& performance }\end{array}$ & $\begin{array}{l}\text { Creating model and } \\
\text { standards. } \\
\text { Establishing new efficient } \\
\text { systems and processes }\end{array}$ \\
\hline $\begin{array}{l}\text { A USE tool: a 5-stage process } \\
\text { 1. Define the evaluation - for what } \\
\text { 2. Mapping usability-what } \\
\text { 3. Walk through-where \&who } \\
\text { 4. Workshop organization-why } \\
\text { 5. Action plan \& report-who. }\end{array}$ & $\begin{array}{l}\text { Assessment method flow in } \\
\text { gathering \& analysis data- } \\
\text { improving or future solution }\end{array}$ \\
\hline
\end{tabular}




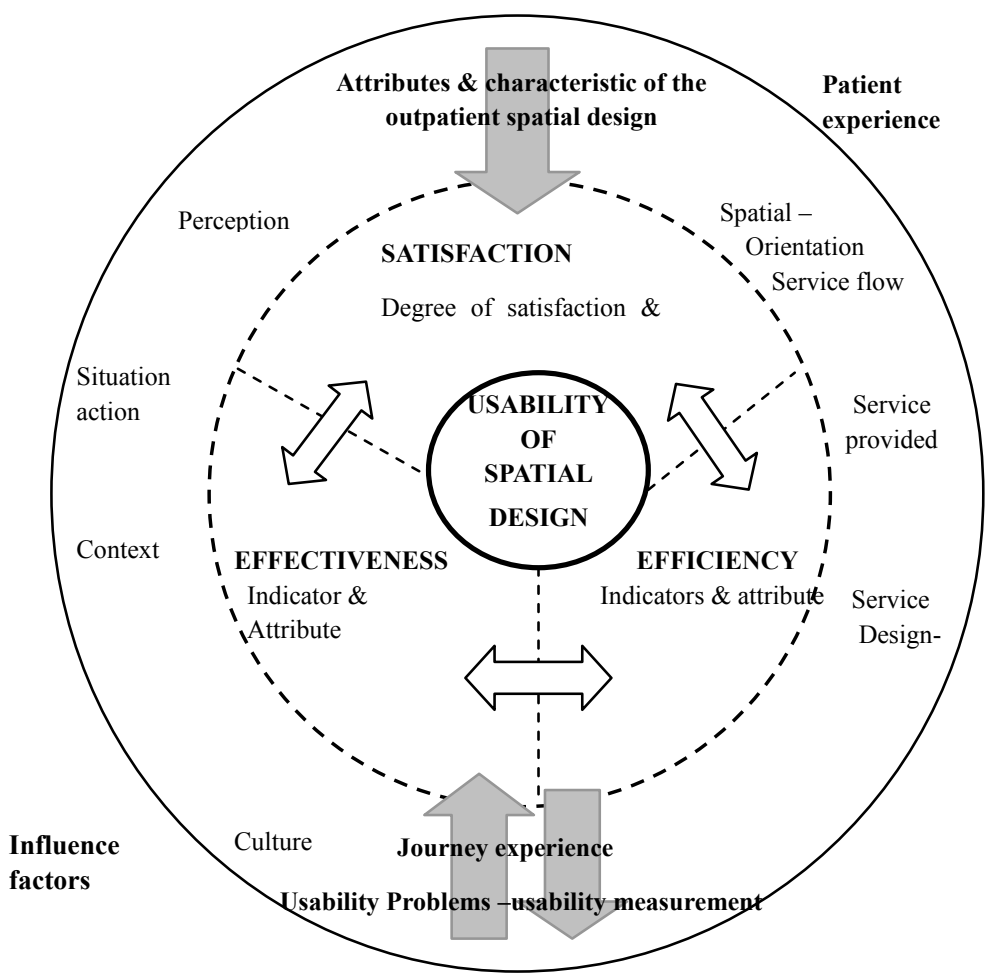

Figure 1 . The attributes and characteristics in achieving usability of outpatient spatial design

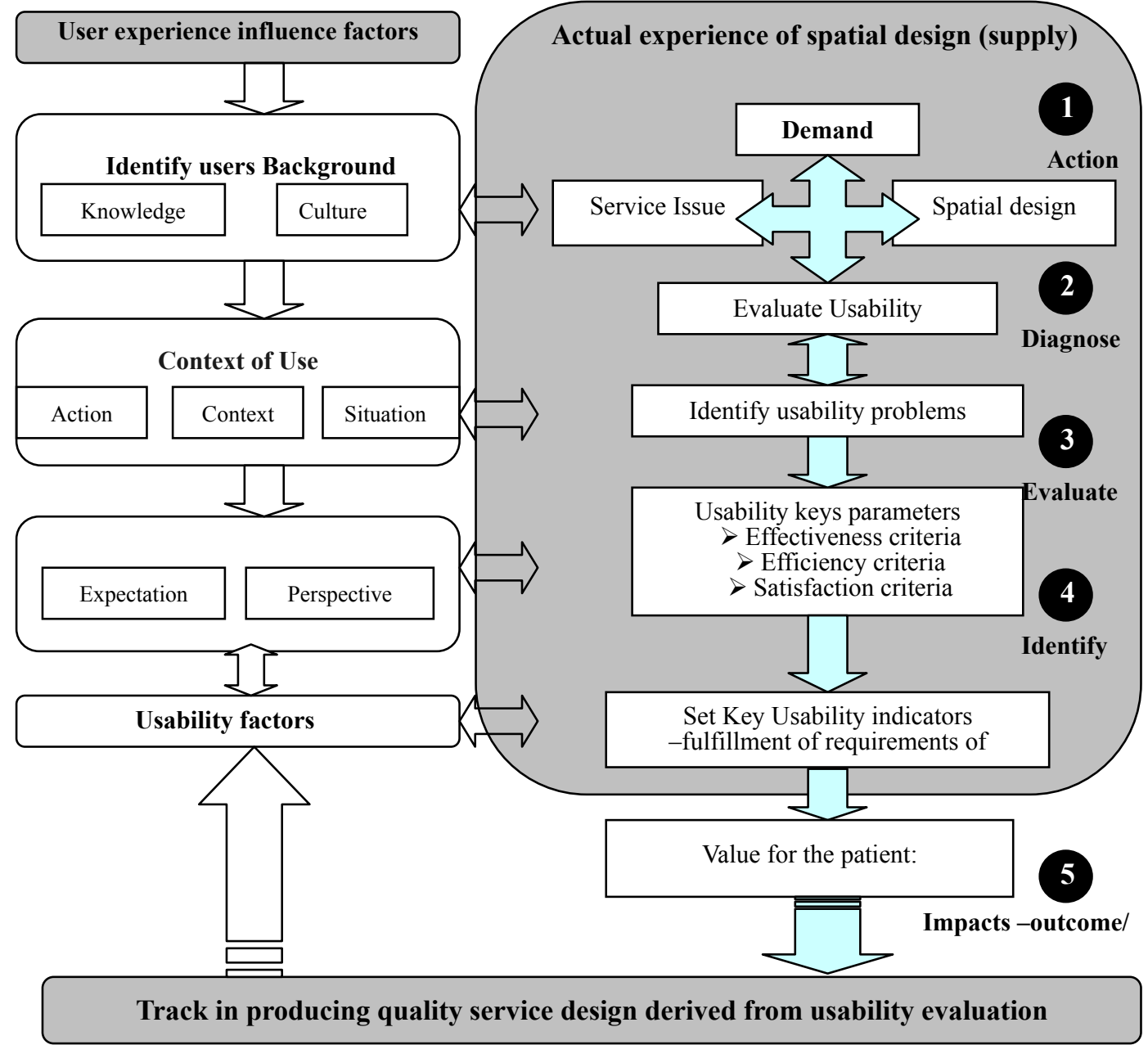

Figure 2. Usability evaluation framework for achieving quality service design 